\title{
O CUIDADO DA ENFERMAGEM AO PACIENTE CIRÚRGICO FRENTE AO ATO ANESTÉSICO
}

\author{
Ana Paula Peçanha Passos \\ Especialista em Centro Cirúrgico/Docente do Curso de Graduação em Enfermagem/ISECENSA/RJ \\ apaula.passos@hotmail.com
}

\section{RESUMO}

A assistência de enfermagem durante o período pós-operatório imediato é muito importante e concentra-se em intervenções destinadas a prevenir ou tratar complicações. Por menor que seja o procedimento cirúrgico, o risco de complicações sempre estará presente. As primeiras unidades de recuperação pós-anestésicas surgiram em 1880 e tem como objetivos proporcionar a recuperação dos pacientes e prevenir e detectar complicações relacionadas ao procedimento anestésico-cirúrgico. O foco na unidade de recuperação pósanestésica é assistir o paciente até que ele tenha se recuperado dos efeitos da anestesia, isto é, até que os seus sinais vitais e as suas funções motoras e sensitivas retornem aos níveis normais.

Palavras-chave: Assistência de Enfermagem; Período pós-operatório; Unidade de Recuperação Pósanestésica.

\section{INTRODUÇÃO}

A enfermagem é uma profissão essencial nos serviços de saúde, que utiliza não só conhecimentos específicos ou relacionados à área de saúde, mas também que integra e aplica conhecimentos derivados de outras áreas, como as ciências sociais, comportamentais, naturais e humanas. Sendo assim, os enfermeiros que atuam no período perioperatório devem fundamentar suas ações na aplicação criativa desses conhecimentos e ter habilidades e competências que visem que visem um cuidado individualizado ao paciente cirúrgico. Devem, também, acompanhar mudanças tecnológicas, econômicas e culturais do campo em que atuam, adaptando-as em seu cotidiano e utilizando-as para subsidiar programas de educação continuada para sua equipe.

O período pós-operatório estende-se desde o momento em que o paciente deixa a sala de cirurgia até a última visita de acompanhamento com o cirurgião. Esse período pode ser tão curto quanto 1 semana ou tão longo quanto vários meses. Durante o período pós-operatório, o cuidado de enfermagem focaliza o restabelecimento do equilíbrio fisiológico do paciente, o alívio da dor, a prevenção das complicações e o ensino do autocuidado do paciente. A avaliação cuidadosa e a intervenção imediata auxiliam o paciente no retorno rápido, seguro e o mais confortável possível para a função ótima. $O$ cuidado contínuo na comunidade, por meio dos cuidados domiciliares, visitas clínicas, visitas de consultório ou acompanhamento telefônico, facilita uma recuperação sem complicações.

A Unidade de recuperação pós-anestésica também chamada de sala de recuperação pósanestésica(RPA), fica localizada adjacente às salas de cirurgia. Os pacientes ainda sob anestesia ou recuperando-se da anestesia são colocados nessa unidade para o fácil acesso a enfermeiras experientes, altamente competentes, anestesiologistas ou anestesistas, cirurgiões, monitoração e suporte pulmonar e hemodinâmico avançados, equipamento especial e medicamentos. A Unidade é mantida tranqüila, limpa e livre de equipamento desnecessário. Essa área é pintada em cores suaves e agradáveis e possui iluminação indireta, um teto á prova de som, equipamento que controla ou elimina o e boxes isolados, porém visíveis, para os pacientes agitados. A Unidade também deve ser bem ventilada. Esses aspectos beneficiam o paciente, pois o ajudam a diminuir a ansiedade e promover o conforto. $\mathrm{O}$ leito da Unidade propicia acesso fácil ao paciente, é seguro e de fácil mobilidade; pode ser colocado em posição a fim de simplificar e facilitar o cuidado, como suportes intravenosos (IV), grades laterais e freios nas rodas. 
Este artigo tem como objetivos descrever as responsabilidades da enfermagem da unidade de recuperação pós-anestésica na prevenção de complicações pós-operatórias imediatas; identificar os problemas pós-operatórios comuns e o tratamento de enfermagem; e descrever os principais diagnósticos de enfermagem no pós-operatório.

\section{METODOLOGIA}

Trata-se de um estudo de revisão bibliográfica descritiva sobre a construção de um registro de linguagem padronizada para coleta de dados perioperatória, utilizando-se o modelo focado no paciente perioperatório.

\section{FUNDAMENTAÇÃO TEÓRICA}

Transferir o paciente pós-operatório da sala de cirurgia para a RPA é responsabilidade do anestesiologista ou anestesista. Durante o transporte da sala de cirurgia para a RPA, o fornecedor da anestesia permanece na cabeceira da maca (para manter a via aérea), e um membro da equipe cirúrgica permanece na extremidade oposta. O local da operação deve ser considerado com atenção sempre ao movimentar o paciente recém-operado. Assim, nas operações de tireóide, a cabeça do paciente não pode sofrer hiperextensão; em amputações do seio, o braço do lado operado é mantido junto ao corpo; na nefrectomia, não é permitido ao paciente deitar-se do lado afetado, e assim por diante. Após a transferência da mesa cirúrgica para a cama, todas as sondas, drenos e cateteres devem ser posicionados corretamente.

Tão logo seja colocado na cama ou maca, o paciente deve ser coberto com cobertores leves. A cama ou maca deve ser provida de grades laterais assegurando proteção para o paciente, no caso de passar por um estágio de excitação ao se recuperar do anestésico. Pacientes entubados, com monitoração invasiva e com possível agitação durante o transporte, devem ser antecipadamente informados aos responsáveis pela Recuperação Pós-Anestésica.

O que acontece na sala de cirurgia pode afetar a assistência pós-operatória imediata do paciente, bem como a recuperação geral. Para transmitir o que ocorreu na sala de cirurgia, espera-se que o anestesiologista forneça um relato detalhado e completo para o enfermeiro que assume a assistência pós-operatória do paciente anestesiado. A enfermeira que admite o paciente na RPA revê as seguintes informações com o anestesiologista ou anestesia:

-Diagnósticos médicos e tipo de cirurgia realizada;

·Histórico médico pregresso e alergias pertinentes;

-Idade e condição geral do paciente, permeabilidade da via aérea, sinais vitais;

-Anestésico e outros medicamentos empregados durante o procedimento (p.ex., opióides e outros agentes analgésicos, relaxantes musculares, antibióticos);

-Quaisquer problemas que tenham ocorrido na sala de cirurgia que poderiam influenciar o cuidado pósoperatório (p.ex., hemorragia extensa, choque, parada cardíaca);

.Patologia encontrada (se a malignidade for um problema durante a cirurgia, a enfermeira precisa saber se o paciente e/ou família foram informados);

-Líquido administrado, perda sanguínea estimada e líquidos de reposição;

-Qualquer equipo drenos, cateteres ou outros dispositivos de suporte;

-Informações específicas sobre as quais o cirurgião, anestesiologista ou anestesista desejam ser notificados (p.ex., pressão arterial ou frequiência cardíaca abaixo ou acima de um nível especificado).

Antes de receber o paciente, observar o funcionamento correto dos aparelhos de monitoração e aspiração, equipamento de oxigenoterapia e todos os outros equipamentos. Ao receber o relato do anestesiologista, o enfermeiro simultaneamente pode avaliar a condição do paciente e individualizar o plano de prescrições de enfermagem. Os fatores de avaliação inicial relatados ao anestesiologista são os sinais 
vitais do paciente (pressão arterial, pulso, respiração e temperatura), oximetria de pulso e nível de consciência. Também podem ser indicados monitorização cardíaca, leituras de pressão e débito urinário. Os sinais vitais são monitorados a cada 15 minutos, ou com maior freqüência se a condição do paciente o exigir.

A Sociedade Americana de Enfermeiros Pós-anestésicos, conforme sancionado pela Sociedade Americana de Anestesiologistas, recomenda que todos os dados de avaliação sejam reunidos e documentados no registro pós-operatório do paciente. O enfermeiro responsável pela sala de operação deve sistematizar o registro das informações, mantendo vínculo ativo com os profissionais da saúde, além de oferecer à equipe de enfermagem condições para atuar com o cliente de maneira efetiva, planejada e segura. Quando o cliente é admitido na RPA, os profissionais devem notificar a chegada do cliente à área de cuidados, o que permite que a equipe de enfermagem informe os familiares sobre a evolução cirúrgica do cliente e os possíveis motivos para atrasos que possam ter ocorrido. Em geral, a enfermeira deve aconselhar os membros da família a permanecer na área de espera designada, de modo que possam ser encontrados, quando o cirurgião chegar para explicar a condição do cliente. É responsabilidade do cirurgião descrever o estado do cliente, os resultados da cirurgia e complicações que possam ter sido encontradas. A enfermeira pode ser um recurso valioso para a família, caso complicações tenham surgido na fase operatória.

Conseqüentemente, o planejamento da assistência é de suma importância na recuperação do paciente e na prevenção de complicações pós-operatórias. A fase de recuperação pós-anestésica é crítica e requer atenção e vigilância constante sobre os pacientes, pois é nela que podem ocorrer complicações conseqüentes à ação depressora das drogas anestésicas sobre o sistema nervoso e ao próprio ato cirúrgico. No período pósoperatório o paciente fica vulnerável a diversas complicações, especialmente as de origem respiratória, circulatória, gastrointestinal. O conhecimento das principais complicações é fundamental, para promover a rápida recuperação do paciente, evitar a infecção hospitalar e reduzir gastos.

A utilização de um instrumento facilita o preenchimento dos dados do paciente, e eles são registrados com maior rapidez, permitindo uma avaliação racionalizada das condições físicas do paciente. Conseqüentemente, isso fará com que a assistência de enfermagem na RPA torne-se mais próxima do paciente e humanizada. São importantes as anotações de enfermagem, registrando horários, uso de manta térmica, por exemplo, medicações, curativos, drenos, sondas, cateteres, infusões, sangramento e outros procedimentos realizados. É necessário uniformizar os critérios de avaliação dos clientes por meio de treinamento da equipe multiprofissional.

Após ser submetido à avaliação do enfermeiro e do anestesista, o paciente poderá receber alta da RPA. Nessa avaliação, consideram-se as drogas utilizadas na anestesia, o nível de consciência do paciente e o seu estado geral. O paciente deverá apresentar: padrão respiratório eficaz, com troca gasosa adequada; presença de reflexos glossofaríngeos; estabilização dos sinais vitais; retorno do nível de consciência; mínimo de dor possível; sinais de volemia adequada, como volume urinário de $30 \mathrm{~mL} / \mathrm{h}$ e PA estabilizada no nível de normalidade do paciente; ausência de sangramentos por sondas ou drenos. O enfermeiro deverá avaliar se as ações implementadas foram eficazes durante todo o período pós-operatório.

Muitos hospitais utilizam um sistema de pontuação (ex., escore de Aldrete) para determinar a condição geral do paciente e sua aptidão para a transferência da RPA. Durante todo o período de recuperação, os sinais físicos do paciente são observados e avaliados por meio de um sistema de pontuação baseado em um conjunto de critérios objetivos. Esse guia de avaliação, uma modificação do sistema de escore de Apgar utilizado para avaliar neonatos, possibilita um exame mais objetivo da condição do paciente na RPA. O paciente é avaliado a intervalos regulares (ex., a cada 15 ou 30 minutos) e o escore é totalizado no registro da avaliação. Os pacientes com um escore menor que 7 devem permanecer na RPA até que sua condição melhore ou que eles sejam transferidos para uma área de cuidados intensivos, dependendo de seus escores basais pré-operatórios.

\subsection{Tratamento de enfermagem}

As metas do tratamento de enfermagem para o paciente na RPA consistem em fornecer o cuidado até que o paciente tenha se recuperado dos efeitos da anestesia (ex., até a retomada das funções motora e sensorial), esteja orientado, apresente sinais vitais estáveis e não mostre evidências de hemorragia nem 
outras complicações. O cuidado de enfermagem deve focalizar a monitoração e manutenção dos estados respiratórios, circulatório, hidroeletrolítico e neurológico, bem como o controle da dor.

Avaliações freqüentes e criteriosas do nível de saturação de oxigênio no sangue, freqüência e regularidade do pulso, profundidade e natureza das respirações, coloração da pele, nível de consciência e a capacidade de responder aos comandos são os marcos do cuidado de enfermagem na RPA. A enfermeira realiza uma avaliação basal, depois verifica o sítio cirúrgico para a drenagem ou hemorragia e se certifica de que todos os tubos de drenagem e linhas de monitoração estão conectados e funcionantes. Depois da avaliação inicial, os sinais vitais são monitorados e o estado físico geral do paciente é examinado, pelo menos, a cada 15 minutos.

A principal meta no período pós-operatório imediato consiste em manter a ventilação pulmonar e, dessa maneira, evitar a hipoxemia (oxigênio reduzido no sangue) e a hipercapnia (excesso de dióxido de carbono no sangue). Ambas podem ocorrer se a via aérea estiver obstruída e a ventilação estiver reduzida (hipoventilação). Uma das maiores preocupações da enfermeira deve residir na obstrução da via aérea. No cliente pós-anestésico, a língua provoca a maioria dos casos de obstrução da via aérea. Além de verificar as prescrições médicas e a execução da administração de oxigênio suplementar, a enfermeira avalia a freqüência e a profundidade respiratória, a facilidade das respirações, a saturação de oxigênio e os sons respiratórios.

O cliente está em risco de complicações cardiovasculares decorrentes da perda sanguínea real ou potencial proveniente do sítio cirúrgico; de efeitos colaterais da anestesia; de desequilíbrios hidroeletrolíticos; e de depressão dos mecanismos normais de regulação da circulação. Avalie o eletrocardiograma para o ritmo e freqüência cardíaca. Avalie a pressão arterial e o pulso para as tendências, em lugar dos valores absolutos. A pressão arterial decrescente e a frequiência de pulso aumentada no cliente pós-operatório são significativas porque podem significar hemorragia ou choque. Os agentes anestésicos podem afetar de várias formas a pressão arterial. A hipotensão é provavelmente a complicação cardiovascular mais comum observada no período pós-operatório, sendo causada na maioria das vezes por uma diminuição do volume sanguíneo circulante. Também inspecione a pele do cliente quanto à coloração (ex., hipocorda, cianótica), temperatura e sudorese (transpiração). A pele pálida, cianótica, fria ou pegajosa pode indicar perfusão tissular prejudicada, possivelmente por choque.

A dor é um sintoma subjetivo em que o paciente exibe uma sensação de desconforto. A estimulação ou trauma de determinadas terminações nervosas, em conseqüência da cirurgia, provocam a dor. Quando os clientes despertam da anestesia geral, a sensação de dor fica proeminente. A dor pode ser percebida, antes que a consciência plena seja recuperada. A dor incisional aguda faz com que os clientes fiquem agitados e pode ser responsável por alterações nos sinais vitais. A avaliação do desconforto do cliente e a avaliação da dor são funções essenciais da enfermagem. Além de monitorar o estado fisiológico do paciente e de controlar a dor, a enfermeira da RPA fornece apoio psicológico em um esforço para aliviar os medos e preocupações do paciente.

A náusea e o vômito são problemas comuns na RPA. A enfermeira deve intervir no primeiro relato de náusea do paciente para controlar o problema em lugar de aguardar que ela progrida até o vômito. Muitos medicamentos estão disponíveis para controlar a náusea e o vômito sem sedar excessivamente o paciente; eles geralmente são administrados durante a cirurgia, bem como na RPA. Freqüentemente, náuseas e vômitos podem ser aliviados por identificação do fator causador (distensão gástrica, hipotensão, administração de narcóticos) e por intervenção apropriada.

\subsection{Diagnósticos de Enfermagem / Prescrição de Enfermagem}

- Dor Aguda relacionada á incisão cirúrgica e trauma tecidual.

- Observar idade, peso, condições médicas/psicológicas coexistindo, sensibilidade a analgésicos e curso intra-operatório;

- Aplicar técnicas complementares para alívio da dor, como relaxamento e distração; 
- Observar a presença de ansiedade/medo, e relacioná-los com a natureza e o preparo para o procedimento;

- Avaliar os sinais vitais, observando taquicardia, hipertensão e aumento da respiração, mesmo se o paciente nega a dor.

- Padrão Respiratório Ineficaz, relacionado à depressão do centro respiratório.

- Manter as vias aéreas do paciente desobstruídas pela elevação da cabeça, hiperextensão da mandíbula, cânula orofaríngea;

- Auscultar os sons respiratórios;

- Observar frequiência e a profundidade respiratórias, expansão do tórax, uso de músculos acessórios, retração ou dilatação das narinas, cor da pele; observar o fluxo de ar;

- Monitorar os sinais vitais continuamente.

- Débito Cardíaco Diminuído relacionado ao choque ou hemorragia.

- Avaliar a pressão arterial e a frequiência cardíaca, comparando com os resultados pré-operatórios;

- Avaliar a coloração e a umidade da pele;

- Avaliar os pulsos periféricos e o tempo de enchimento capilar, principalmente em cirurgias vasculares e ortopédicas;

- Monitorizar/registrar arritmias cardíacas;

- Realizar controle hídrico.

- Risco de desequilíbrio da temperatura corporal relacionado ao ambiente cirúrgico e agentes anestésicos.

- Monitorar a temperatura do paciente e do ambiente;

- Comunicar valores de temperatura axilar abaixo de $35^{\circ} \mathrm{C}$;

- Aquecer o paciente com cobertores ou mantas térmicas, quando necessário;

- Substituir roupas molhadas por secas;

- Evitar descobrir os pacientes sem necessidade.

- Risco para Infecção relacionado á procedimentos invasivos e exposição ao ambiente.

- Assegurar o manuseio asséptico dos acessos intravenosos;

- Utilizar técnicas assépticas no cuidado da ferida operatória;

- Verificar esterilidade de todos os itens manufaturados;

- Avaliar sinais de infecção/sinais flogísticos (dor, calor, edema);

- Examinar a pele quanto a lesões ou irritações, sinais de infecção;

- Aplicar curativos estéreis.

\section{CONSIDERAÇÕES FINAIS}

Diante do exposto sobre a assistência de enfermagem na recuperação pós-anestésica, podemos afirmar que os cuidados de enfermagem ao paciente que se encontra no período pós-operatório imediato, ou seja, ao paciente que está se recuperando da anestesia na RPA

O período pós-operatório corresponde ao período em que o paciente se recupera da anestesia e tem início com a transferência do paciente para a sala de recuperação pós-anestésica. 
Com a modernização da anestesia, cresceu a demanda por um cuidado pós-anestésico sistematizado. Ao mesmo tempo, houve uma maior oferta de tecnologia, o que possibilitou a avaliação do paciente em pósoperatório imediato com maior precisão e rapidez. Observou-se, assim, redução de morbidade e mortalidade dos pacientes, bem como diminuição do período de hospitalização. Não se pode prever como será o futuro com exatidão; entretanto, acredita-se que as salas de recuperação pós-anestésica e os enfermeiros continuarão desempenhando um papel fundamental para o sucesso da recuperação de pacientes submetidos a procedimentos anestésico-cirúrgicos.

Para tanto, é necessário que a enfermagem esteja preparada, de forma técnica e científica, para prestar uma assistência eficaz e segura e para acompanhar as constantes mudanças tecnológicas, econômicas e culturais do campo em que atuam.

\section{REFERÊNCIAS}

CRAVEN, Ruth F.; HIRNLE, Constance J. Fundamentos de Enfermagem. Saúde e Função Humanas. $4^{\text {a }}$ edição, Rio de Janeiro: Guanabara Koogan, 2006.

DOENGES, Marilynn E.; MOORHOUSE, Mary F.; GEISSLER, Alice C. Planos de Cuidado de Enfermagem. $5^{\text {a }}$ edição, Rio de Janeiro: Guanabara Koogan, 2003.

DU GAS, Beverly W. Enfermagem Prática. 4ª edição, Rio de Janeiro: Guanabara Koogan, 2005.

Diagnósticos de Enfermagem da NANDA. Definições e classificações 2007/2008. Editora Artmed. Porto Alegre, 2008.

HUDAK, Carolyn M.; GALLO, Barbara M. Cuidados Intensivos de Enfermagem. Uma abordagem holística. $6^{\text {a }}$ edição, Rio de Janeiro: Guanabara Koogan, 1997.

HUTTEL - HARGROVE, Ray A. Enfermagem Médico-Cirúrgica. Série de Estudos em Enfermagem. $2^{\mathrm{a}}$ edição, Rio de Janeiro: Guanabara koogan, 1998.

NETTINA, Sandra. Prática de Enfermagem. 7ª edição, Rio de Janeiro: Guanabara Koogan, 2003.

POSSARI, João F. Centro Cirúrgico. Planejamento, Organização e Gestão.2a edição, São Paulo: Iátria, 2006.

POTTER, Patrícia A.; PERRY, Anne G. Fundamentos de Enfermagem. $5^{\text {a }}$ edição, Rio de Janeiro: Guanabara Koogan, 2004.

SMELTZER, Suzanne C. e Brenda G. Bare. Tratado de Enfermagem médico cirúrgico. 10ª edição, Rio de Janeiro: Guanabara Koogan, 2006. 